rently pressure upon the buccal nerve of the lower division of the fifth. There appeared very slight deformity.

On his next visit (January 5th) there was less pain, and he could open the jaw slightly, the other symptoms remaining much the same.

\section{HOMERTON SMALL-POX ASYLUM.}

ERMORRHAGIC SMALL-POX ASSOCIATED WITH TETANUS. (Under the care of Dr. Garton.)

THE following case presents features of an unusual character, both as regards the tetanoid symptoms and the amount and character of the eruption. It reads almost like a case of cerebro-spinal meningitis, and had it occurred at Dublin in 1866, instead of at London in 1872, it would in all probability have been so designated.

C. $\mathrm{O}$ - aged seventeen, an errand-boy, was admitted on the evening of January 6 th. The patient was quite well until the 3rd January, when he complained of shivering and headache. On admission, there were a few variolous papules on the face, trunk, and extremities, of a dark hæmorrhagic character, with numerous dark-purple spots on various parts of the body. He was completely unconscious; the mouth widely open; the face distorted; and the pupils dilated, the left more than the right. He was constantly shouting out, but no answer could be obtained to any question. He lay upon his left side with his legs drawn up; and when placed on his back he rested upon the occipnt and the heels, the body representing a complete arch. Fluid introdnced into the mouth was rejected through the nostrils. Pulse 120 lungs clear. Pressure upon the neck by pinching produced no effect. Swallowing being impossible, enemata of beef-tea \&c. were given; and small doses of chloral hydrate produced slight relaxation of the muscular contraction, but otherwise did not appear to do any good. The patient remained in this condition until the afternoon of Jan. 8th, when he died.

Post-mortem exanination. - On removing the calvaria, considerable difficulty was experienced owing to the firm adhesion of the dura mater. The brain was deeply congested over its whole surface, and appeared softer than natural. No fluid was found in the ventricles. On the under surface of the pons Varolii, extending along the under surface of the medulla oblongata (where it abruptly ended), was a thickish layer of concrete pus. On the posterior surface of the medulla oblongata there was a similar lajer of pus, which appeared to end at the junction of the medulla oblongata with the cord, the superior two inches of which were free from exudation; but, with this exception, the posterior surface of the cord throughout its entire length was covered with an exudation like that already described. The cauda equina was infiltrated with fluid pus. The anterior surface of the cord was quite free from exudation; the cord itself was considerably congested. On examination by the microscope, numerous cells were seen; these cells were full of granules, which disappeared on the addition of acetic acid. No change was observed in the nerve-cells.

\section{ST. BARTHOLOMEW'S HOSPITAL, CHATHAM.}

DIFFUSED POPLITEAL ANEURISM (LEFT); AMPUTATION OF THIGH; SURSEQUENT FEMORAL ANEURISM OF

RIGHT THIGH; LIGATURE OF FEMLRAL ARTERY ; RECOVERY.

(Under the care of Mr. A. W. Nankivelu.)

E. $P_{\text {- }}$, a labonrer, aged thirty-three, admitted July 5 th, 1871, with a large popliteal aneurism of the left leg. The knee on the affected side measured two inches more than the sound one. Carte's tourniquet was applied several times daily, but the patient was unable to bear the pressure for more than half an hour at any one time. On the eighth day after his admission be complained of severe pain in the calf of the leg and foot, and there was some celema of the limb. The pain in the limb continued to increase, the odema of the leg got gradually more marked, and the aneurismal sac became decidedly tender. No pulsation could be detected in the tibial arteries. On the 27 th of July the limb became distinctly gangrenons, and it was determined to amputate the thigh in the lower third above the aneurism. This was accomplished by means of anteroposterior flaps.

On examining the limb after removal, it was found that the sac had ruptured between the heads of the gastrocnemius, the whole of the calf being infiltrated with blood The sac of the aneurism extended from the upper boundaries of the popliteal space to about two inches below the bifurcation of the artery. After the operation the man made a good recovery, and was discharged cured on Oct. 11 th, 1871 .

On Nov. 22nd, 1871, the patient was readmitted, suffering from a femoral anourism of the right thigh. The aneurism was fusiform in shape, and occupied the whole of Hunter's canal. He would not permit the application of pressure. On Nov. 27 th the femoral artery was tied with a carbolised catgut ligature in the usual situation. The wound was dressed antiseptically. Lac plaster was applied at intervals up to Dec. $28 \mathrm{th}$, when the wound was found to be entirely healed. Some suppuration took place, but it never became putrefactive. He was discharged cured on January 10th, 1872 .

The treatment adopted when the popliteal aneurism became diffused was, Mr. Nankivell thinks, judicious. Had the artery been ligatured when the sac ruptured, it would probably have hastened the gangrene, thus necessitating a further operation, and also compelling removal of the limb at a higher level-viz., above the ligature. The recurrence of the disease in the right thigh after removal of the left leg is interesting as showing a disposition to disease of the arteries. The formation of the second aneurism cannot be put down to any strain or blow, as the man was leading a quiet life at home. It might perhaps justly be assigned to constitutional causes.

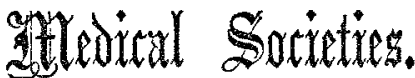

\section{CLINICAL SOCIETY OF LONDON.}

FRIDAY, JAN. 26TH, 1872.

Sir W. W. Gulu, Bart., F.R.S., Preidinent, in the Chair.

The President delivered the Annual Address, which is fully reported elsewhere in our columns, and for which a unanimous vote of thanks was accorded by the meeting.

Mr. Cooper Fonster read two cases of Popliteal Aneurism: one of a man at Guy's Hospital, in which for two months pressure, with and withont chloroform and flexion, were used, with, at last, a cure of the disease; and the other of a gentleman, in which digital compression was used for three hours and a half, and at the end of that time complete cure was effected. Mr. Forster believed the latter case to show the shortest time on record in which a cure had been effected by any means. The first patient pointed to the necessity of perseverance in the treatment to ensure success. Mr. Forster did not bring these cases forward as any novelty, but rather with the idea of eliciting from surgeons their views as to the advisability or otherwise of persevering in the plan of compression or flexion without the use of the knife. He alluded to the difference in the Scotch and Irish schools; and, though by no means a follower implicitly of either one or the other, he still believed that, in cases of popliteal aneurism, if the surgeon has confidence in his treatment, the cases must be very few in which compression would not be found sufficient for the cure of this disease; and stated that he had never yet tied the femoral artery for the cure of this form of aneurism, though once or twice the tediousness of the recovery of the patient almost induced him to do so.

Mr. ERNEST HART remarked that these cases indicated some very important points in surgical pathology. The first efforts in the way of curing aneurisms were directed to obtaining complete closure of the artery. All plans adopted, however, caused an intolerable amount of pain, and so the Irish surgeons adopted means to slacken the current of blood through the vessel, and so to favour the deposit of fibrin. Mr. Hart believed that the rapid mode was the best; that hence chloroform was a most valuable ally, and that numberless cases are records of cures 